\title{
Influência das condições de cultivo na composição da semente e do óleo de gergelim
}

\author{
Rosemar Antoniassi ${ }^{1}$, Nair Helena Castro Arriel ${ }^{2}$, Elisabeth Borges Gonçalves ${ }^{3}$, Sidinéa Cordeiro de Freitas ${ }^{4}$, \\ Dirceu Luís Zanotto ${ }^{5}$,Humberto Ribeiro Bizzo ${ }^{6}$
}

\section{RESUMO}

Neste trabalho foram avaliadas sementes de 14 genótipos de gergelim, oriundos de ensaios realizados em delineamento ao acaso, com cinco repetições, cultivados em Patos, na Paraíba, e em Barbalha, no Ceará, em ambientes de sequeiro e irrigado, respectivamente. As sementes foram avaliadas quanto à composição centesimal e quanto ao teor de aminoácidos. No óleo, foram determinados o perfil em ácidos graxos e esteróis, além de características do padrão de identidade e qualidade. Foram observadas diferenças significativas $(p<0,05)$ entre os locais para o teor de óleo e de proteína, sendo o teor de óleo superior para Barbalha, onde o cultivo foi irrigado. Houve diferença significativa $(\mathrm{p}<0,05)$ entre as médias de Patos e de Barbalha para os ácidos graxos, sendo que os teores de ácidos esteárico (C18:0) e oleico (C18:1) foram maiores para Patos, enquanto o de ácido linoleico (C18:2) foi maior para Barbalha. Quanto aos teores de esteróis, campesterol, estigmasterol e delta 5 avenasterol, foram maiores para o óleo das amostras de Barbalha, enquanto o de sitosterol foi maior para amostras de Patos $(\mathrm{p}<0,05)$. Algumas diferenças foram observadas quanto a ácidos graxos, esteróis, densidade, índice de refração e padrão de identidade, para o óleo de gergelim, do Codex Alimentarius (2001), reforçando a necessidade de construir-se uma base de dados nacional, que possa subsidiar futuras alterações neste padrão.

Palavras-chave: óleo, esteróis, ácidos graxos.

\section{ABSTRACT}

\section{Effect of cultivation conditions on the composition of sesame seed and oil}

Fourteen selected sesame genotypes were grown in Patos, Paraíba State, Brazil and Barbalha, Ceará State, Brazil, and the trials were at a randomized block design with five replicates under non-irrigated and irrigated conditions, respectively. Seeds were evaluated for oil yield and chemical composition, while defatted meal was analyzed for amino acids content. The fatty acids and sterols profiles were also evaluated, as well as the characteristics for identity and oil quality. The differences observed between genotypes in the same area were small. However, significant differences ( $p$ $<0.05$ ) between the areas for oil content and protein were observed, with higher oil content found for genotypes in Barbalha, where the crop was irrigated. Higher amounts of stearic (C18: 0) and oleic acids (C18: 1) were observed for the oil from Patos, while for linoleic acid (C18:2) a higher content was found in Barbalha oil. As for sterols, campesterol, stigmasterol and delta 5 avenasterol were more abundant for samples from Barbalha, and sitosterol for samples from Patos ( $\mathrm{p}<0.05$ ). Some figures observed for some fatty acids, sterols, density and refractive index diverged from the identity characteristics described in Codex Alimentarius (2001), reinforcing the need to set up a national database that can support future changes in this standard.

Key words: oil, sterols, fatty acids.

\footnotetext{
Recebido para publicação em 25/05/2012 e aprovado em 25/04/2013.

${ }^{1}$ Engenheira de Alimentos, Doutora. Embrapa Agroindústria de Alimentos, Avenida Américas, 29501, 23020-470, Rio de Janeiro, Rio de Janeiro, Brasil. rosemar@ctaa.embrapa.br (autora para correspondência)

${ }^{2}$ Engenheira-Agrônoma, Doutora. Embrapa Algodão, Caixa Postal 174, 58107-720, Campina Grande, Paraíba, Brasil. nair@ cnpa.embrapa.br

${ }^{3}$ Estatística, Doutora. Embrapa Agroindústria de Alimentos, Avenida Américas, 29501, 23020-470, Rio de Janeiro, Rio de Janeiro, Brasil. goncaleb@ctaa.embrapa.br

${ }^{4}$ Engenheira Química, Doutora. Embrapa Agroindústria de Alimentos, Avenida Américas, 29501, 23020-470, Rio de Janeiro, Rio de Janeiro, Brasil. sidi@ctaa.embrapa.br

${ }^{5}$ Biólogo, Mestre. Embrapa Suínos e Aves, Caixa Postal 21, 89700-000, Concórdia, Santa Catarina, Brasil. zanotto@cnpsa.embrapa.br

${ }^{6}$ Químico, Doutor. Embrapa Agroindústria de Alimentos, Avenida Américas, 29501, 23020-470, Rio de Janeiro, Rio de Janeiro, Brasil. bizzo@ctaa.embrapa.br
} 


\section{INTRODUÇÃO}

O gergelim pertence ao gênero Sesamum, família Pedaliaceae; possui 36 espécies, a maioria silvestre, sendo Sesamum indicum L. a principal fonte do gergelim comercial (Namiki, 2007). Acredita-se que o gergelim seja uma das culturas mais antigas do mundo, cultivada na Babilônia e Assíria há 4000 anos (Hwang, 2005).

O gergelim é cultivado em muitos países, sendo Burma (Myanmar), Índia, Sudão e China, responsáveis por 60\% da produção mundial. O gergelim é, em sua maior parte, utilizado para produção de óleo, mas muitos produtos são obtidos a partir de suas sementes (Elleuch et al., 2007).

De acordo com o IAC (2010), no Brasil, a produção de gergelim oscila entre 3.000 e 5.000 toneladas anuais, concentrada nos Estados de Mato Grosso e Goiás, sendo utilizada pela indústria alimentícia do Estado de São Paulo. De acordo com dados da FAO (2012), a área plantada de gergelim, no Brasil, de 2009 a 2011, foi de 7.000 a 9.000 ha, com produção de 5.000 a 6.000 toneladas e produtividade de $640 \mathrm{~kg} / \mathrm{ha}$.

O óleo de gergelim apresenta altos teores de ácidos graxos polinsaturados; no entanto, a estabilidade oxidativa do óleo é elevada, em virtude da presença de lignanas, sesamolina e sesamina e de seus produtos de degradação, sesamol e sesamolinol, que são potentes antioxidantes (Hwang, 2005).

Namiki (2007) apresenta, em recente revisão, estudos sobre os benefícios do gergelim para a saúde humana. $\mathrm{O}$ efeito antienvelhecimento do gergelim foi atribuído ao efeito sinergístico entre os tocoferóis e lignanas, além de redução de colesterol no sangue, em virtude da aceleração da decomposição de álcool no fígado, atividade antihipertensiva e anticarcinogênica, dentre outras.

Pouco se conhece sobre a composição do gergelim do Brasil e quanto à variabilidade de sua composição, em relação às condições de cultivo.

Neste trabalho, 14 genótipos de gergelim, desenvolvidos pela Embrapa Algodão, foram cultivados em Patos, na Paraíba, e em Barbalha, no Ceará, respectivamente, em condições de sequeiro e sob irrigação, e as composições da semente e do óleo foram comparadas.

\section{MATERIAL E MÉTODOS}

As sementes de gergelim foram oriundas de um Ensaio de Linhagens de gergelim, do programa de melhoramento de gergelim, realizado em duas Estações Experimentais da Embrapa Algodão, situadas nos municípios de Patos, Paraíba e em Barbalha, Ceará.

$\mathrm{O}$ experimento de Patos foi realizado no ano agrícola de 2001, em regime de sequeiro. Patos situa-se no Seridó Paraibano, na região semiárida do nordeste do Brasil, estando compreendido entre os paralelos $06^{\circ} 59^{\prime}$ e $07^{\circ} 00$ ' de latitude sul e os meridianos de $37^{\circ} 18^{\prime} 08^{\prime \prime}$ e $37^{\circ} 20^{\prime} 38$ " de longitude W.Gr., com altitude de $270 \mathrm{~m}$. O clima é do tipo Bsh, segundo a classificação de Köppen (Brasil, 1972), com temperatura anual média máxima de $32,9^{\circ} \mathrm{C}$ e mínima de $20,8^{\circ} \mathrm{C}$ e umidade relativa de $61 \%$, tendo normal pluviométrica de 711,7 mm anuais (Embrapa, 1991; Arriel, 2006). O solo da área experimental foi classificado como Luvissolo hipocrômico Órtico vértico (Embrapa, 1999).

No experimento conduzido no município de Barbalha, as sementes foram semeadas em solo de textura arenoargilosa, sob irrigação, durante o segundo semestre de 2001. Barbalha está localizado na Chapada do Araripe, Microrregião do Cariri Cearense, a $7^{\circ}$ 19', de latitude Sul, $39^{\circ} 18^{\prime}$ de longitude Oeste e 415,74 m de altitude. Segundo a classificação de Köppen, o clima da região do município, é do tipo Aw' - Tropical chuvoso, com estação chuvosa no outono. Trata-se de um clima seco subúmido, com largo excesso hídrico no inverno e com vegetação durante todo a ano. A temperatura média anual é de $30^{\circ} \mathrm{C}$, com precipitação média anual de $1.160 \mathrm{~mm}$, concentrada nos meses de janeiro a maio (Departamento Nacional de Meteorologia, 1992). A caracterização física média do solo da área define-o como neossolo flúvico.

$\mathrm{Na}$ implantação dos ensaios, após o preparo do solo, as sementes dos genótipos de gergelim foram semeadas manualmente, em sulcos de $5 \mathrm{~cm}$ de largura, $\operatorname{com} 2 \mathrm{~cm}$ de profundidade. Após desbaste definitivo, permaneceram em espaçamento de $1,0 \mathrm{~m}$ x 0,2 $\mathrm{m}$. O manejo ocorreu de acordo com as recomendações técnicas da cultura (Embrapa, 1991; Arriel, 2006). A colheita das plantas ocorreu no momento da maturação fisiológica, ou seja, a partir do amarelecimento dos ramos e flores e início de abertura das cápsulas basais.

Para as análises, as sementes foram congeladas, trituradas em blender e acondicionadas em cartuchos de celulose, para extração do óleo com éter de petróleo (30-60 $)$, em aparelho Soxhlet, por 16 horas. O solvente foi evaporado em rotaevaporador e sob corrente de nitrogênio. As determinações de umidade e de cinzas das sementes foram realizadas segundo os métodos oficiais da AOCS Ca 2c-25 e Ca 11-55, respectivamente (AOCS, 2009). O teor de nitrogênio total das sementes foi determinado segundo o método AOAC 33.2.11 (AOAC, 2010a) e o fator de conversão, utilizado para calcular o teor de proteína, foi de 5,3, segundo AOCS (2009). A análise de fibra bruta foi realizada no farelo desengordurado, segundo o método oficial 4.06.02 da AOAC (2010b) e o teor de fibra da semente foi recalculado. A análise de aminoácidos foi realizada no farelo desengordurado, segundo o método oficial da AOAC 4.1.11 (2010c).

Quanto às análises do óleo, a acidez foi realizada, segundo o método oficial da AOCS (2009), Ca 5a 40; o índice 
de refração foi determinado em refratômetro Abbé, a $40^{\circ} \mathrm{C}$ e, a densidade, em densímetro Parr, a $20^{\circ} \mathrm{C}$.

Para composição do óleo em ácidos graxos, os ésteres metílicos foram obtidos de acordo com Hartman \& Lago (1973). A cromatografia em fase gasosa foi realizada em cromatógrafo gasoso modelo HP 5890, séries II da Hewlett Packard, utilizando-se coluna capilar de sílica fundida, de 60 metros, 0,32 mm de diâmetro interno e $0,25 \mu \mathrm{m}$ de fase estacionária de ciano propilsiloxano, com programação de temperatura de 150 a $200^{\circ} \mathrm{C}$ e taxa de aquecimento de $1,3^{\circ} \mathrm{C} / \mathrm{min}$. O injetor foi mantido à temperatura de $250^{\circ} \mathrm{C}$, no modo de divisão de fluxo (split), na razão de 50:1. Foi injetado um volume de $1 \mu \mathrm{L}$ de solução $2 \%$ em diclorometano. A temperatura do detector de ionização de chama foi de $280^{\circ} \mathrm{C}$ e o fluxo de gás carreador $\left(\mathrm{H}_{2}\right)$ foi de $2,5 \mathrm{~mL} /$ min (medido a $40^{\circ} \mathrm{C}$ ). A identificação dos ésteres metílicos dos ácidos graxos foi realizada por comparação dos tempos de retenção com padrões da NU CHEK (Elysian, MN) números 62, 79 e 87 e a quantificação foi realizada por normalização interna.

Para a análise de esteróis, foi realizada a obtenção da matéria insaponificável do óleo, segundo o Método AOCS Ca 6b-53, AOCS (2009), seguido de fracionamento dos esteróis, por cromatografia de camada delgada preparativa, utilizando-se placas de sílica Gel 60 G (Merck), eluídas em sistema éter de petróleo: éter etílico (70:30), de acordo com método Ch 6-91 (AOCS, 2009). A cromatografia em fase gasosa foi realizada em cromatógrafo gasoso modelo HP 5890, séries II da Hewlett Packard, utilizando-se coluna capilar de sílica fundida, de 25 metros, 0,32 $\mathrm{mm}$ de diâmetro interno e 0,17 $\mu \mathrm{m}$ de fase estacionária de $100 \%$ dimetilpolisiloxano (HP Ultra 1), com programação de temperatura do forno de 250 a $290^{\circ} \mathrm{C}$ e taxa de aquecimento de $3^{\circ} \mathrm{C} / \mathrm{min}$. O injetor foi mantido à temperatura de $300^{\circ} \mathrm{C}$, no modo de divisão de fluxo (split), na razão de 50:1; a quantidade injetada foi de $1 \mu \mathrm{L}$ de solução $2 \%$ em diclorometano. O detector de ionização de chama foi mantido à temperatura de 300 ${ }^{\circ} \mathrm{C}$ e o fluxo de gás carreador $\left(\mathrm{H}_{2}\right)$ foi de $2,5 \mathrm{~mL} / \mathrm{min}$ (medido a $40^{\circ} \mathrm{C}$ ). A quantificação dos esteróis foi realizada por normalização interna. A identificação foi realizada por CGAR/EM (cromatografia gasosa de alta resolução, acoplada a espectrometria de massas), em cromatógrafo Agilent 6890 e detector seletivo de massas Agilent 5973, utilizando-se coluna capilar de sílica fundida de $5 \%$ difenil $95 \%$ dimetilpolisiloxano, temperatura de $200-280^{\circ} \mathrm{C}$, com programação de $5^{\circ} \mathrm{C} /$ minuto. A fonte de íons foi de 70 eV. A identificação da fração esteroídica foi realizada por comparação dos espectros de massa com padrões e com espectroteca de massas (NIST, WILEY).

Os resultados foram comparados pelo teste T-Student para duas médias independentes, relativas aos genótipos de duas localidades, utilizando-se o Excel.

\section{RESULTADOS E DISCUSSÃO}

Os resultados da análise da composição das sementes, do óleo e do farelo desengordurado de amostras de gergelim, cultivadas em Patos, na Paraíba, e em Barbalha, no Ceará, estão apresentados nas Tabelas 1 a 7.

Quanto à composição centesimal, as diferenças encontradas entre os genótipos avaliados na mesma área foram pequenas, mas houve diferença significativa $(\mathrm{p}<0,05)$ entre as médias observadas para as amostras cultivadas em Patos e em Barbalha, em relação aos teores de proteína, cinzas e óleo. Não houve diferença significativa para o teor de fibra bruta. A média do teor de proteína foi maior para as amostras de Patos, enquanto os teores de óleo e de cinzas foram maiores para as amostras de Barbalha, a 5\% de significância (Tabela 1). Não houve diferença para umidade e optou-se por omitir os resultados.

Para as sementes do ensaio conduzido em Barbalha, o teor médio de óleo foi de 55,98\%, enquanto os mesmos genótipos, mantidos em Patos apresentaram um conteúdo médio de óleo nas sementes de 49,64\% (base úmida). Nas condições sob regime de irrigação, o conteúdo de óleo variou de 47,74 a $60,71 \%$ e sob regime de sequeiro a amplitude de variação foi de 47,08 a 53,64\%. De acordo com Egbekun \& Ehieze (1997), a variação no rendimento de óleo de sementes de gergelim ocorre em função de diferenças de genótipos, condições climáticas, estádio de maturação da planta, época de colheita e método de extração usado. Were et al. (2006) relatam que a crescente disponibilidade de água durante o desenvolvimento das cápsulas de gergelim leva a um maior conteúdo de óleo nas sementes. $\mathrm{O}$ ensaio de genótipos de gergelim em Patos foi conduzido sob regime de sequeiro, enquanto, em Barbalha, as plantas foram mantidas sob sistema de irrigação, o que favoreceu o maior conteúdo de óleo nas sementes, observado para a maioria das amostras provenientes do ensaio conduzido sob irrigação. Portanto, os valores dos conteúdos de óleo obtidos das amostras de sementes de gergelim, mantidas sob condições ideais de umidade durante o desenvolvimento das plantas, ratificam os resultados relatados por Egbekun \& Ehieze (1997), com exceção do Tratamento 4, em que, provavelmente, o valor genético superou o fator ambiental.

Hwang (2005) reporta a composição de sementes de gergelim pretas, amarelas e brancas, de diversas procedências, com teor de óleo de 35 a $57 \%$ e, de proteína, variando de 17 a $30 \%$. O autor cita também o teor de fibra, variando de 2 a $20 \%$ e, de cinzas, de 3 a $10 \%$. É provável que os resultados de fibra devam-se às diferenças entre métodos de análise, que não foram citados pelo autor. Ressalta-se que, as colorações das sementes das linhagens avaliadas neste trabalho variaram de creme amarelado ao branco. 
Discrepâncias quanto ao teor de proteína ocorrem em virtude do uso do fator de conversão de nitrogênio para proteína. Jones (1931) relata fatores específicos, considerando-se a composição em aminoácidos e o teor de nitrogênio não proteico, sendo citado o fator de 5,3 como específico para o gergelim, também adotado pela American Oil Chemist's Society (AOCS, 2009) e utilizado neste trabalho.

Resultados encontrados neste estudo são semelhantes aos das faixas citadas por Kemal Unal \& Yalçin (2008) e El Khier et al. (2008), para variedades de gergelim da Turquia e do Sudão, respectivamente.

Para 30 variedades cultivadas no Kenya, em três anos consecutivos, o teor de óleo variou de 28,7 a 51\% (Were et al., 2006), enquanto, para 29 acessos cultivados em dois anos, na Turquia, o teor de óleo variou de 47 a $61 \%$ (Arslan et al., 2007) e os autores reportam que as condições ambientais influenciaram o acúmulo de óleo.
Para variedades de gergelim brasileiras, cultivadas no Estado do Rio de Janeiro, o teor de óleo variou de 50,3 a 55,9\% (Ross et al., 2007). Antoniassi \& Souza (2001) encontraram, para variedades da Embrapa Algodão, cultivadas de 1995 a 1997, teores de proteína de 21 a 25,3\% e, de óleo, de 49,5 a 56,2\%.

Quanto à composição em ácidos graxos do óleo, não houve diferenças significativas para ácido palmítico (C16:0) entre as amostras provenientes de Patos e de Barbalha, com variação de 9,22 a 10,48\%. Houve diferença significativa $(\mathrm{p}<0,05)$ entre as médias de Patos e de Barbalha, para os ácidos esteárico (C18:0), oleico (C18:1) e linoleico (C18:2), sendo que os valores para esteárico e oleico foram maiores para amostras de Patos, enquanto o valor para linoleico foi maior para amostras de Barbalha. Os ácidos graxos predominantes foram o linoleico e oleico, sendo que o ácido linolênico foi detectado até $0,31 \%$, o que é bastante favorável, do ponto de vista da estabilidade oxidativa do óleo (Tabelas 2 e 3 e Figura 1).

Tabela 1. Composição centesimal (base úmida) de semente de genótipos de gergelim (g/100g)

\begin{tabular}{|c|c|c|c|c|c|}
\hline Cultivar & Local de Cultivo & Proteína & Óleo & Fibra bruta & Cinzas \\
\hline T01 & Barbalha - CE & 19,24 & 55,11 & 2,94 & 4,75 \\
\hline T02 & Barbalha-CE & 19,03 & 54,35 & 2,76 & 5,14 \\
\hline T03 & Barbalha - CE & 18,92 & 53,63 & 3,44 & 4,64 \\
\hline T04 & Barbalha - CE & 19,40 & 47,74 & 3,99 & 4,98 \\
\hline T05 & Barbalha-CE & 18,92 & 57,63 & 2,97 & 5,13 \\
\hline T06 & Barbalha-CE & 19,24 & 56,58 & 2,71 & 4,77 \\
\hline T07 & Barbalha-CE & 18,07 & 60,18 & 2,82 & 5,07 \\
\hline T08 & Barbalha-CE & 19,13 & 58,81 & 3,09 & 4,86 \\
\hline T09 & Barbalha - CE & 19,40 & 59,77 & 3,02 & 4,95 \\
\hline $\mathrm{T} 10$ & Barbalha-CE & 20,35 & 60,71 & 2,90 & 5,39 \\
\hline $\mathrm{T} 11$ & Barbalha-CE & 19,35 & 54,02 & 3,81 & 4,76 \\
\hline $\mathrm{T} 12$ & Barbalha - CE & 17,86 & 55,07 & 3,72 & 4,91 \\
\hline T13 & Barbalha-CE & 18,50 & 55,32 & 3,49 & 4,63 \\
\hline $\mathrm{T} 14$ & Barbalha-CE & 17,91 & 54,74 & 3,15 & 5,07 \\
\hline Média & Barbalha-CE & 18,95 & 55,98 & 3,20 & 4,93 \\
\hline T01 & Patos - PB & 24,38 & 49,41 & 2,63 & 4,70 \\
\hline T02 & Patos - PB & 22,31 & 47,69 & 2,84 & 4,64 \\
\hline T03 & Patos - PB & 23,37 & 49,55 & 3,14 & 3,91 \\
\hline T04 & Patos - PB & 22,95 & 50,19 & 2,70 & 4,23 \\
\hline T05 & Patos - PB & 22,90 & 48,47 & 4,43 & 4,22 \\
\hline T06 & Patos - PB & 23,27 & 48,44 & 2,70 & 4,74 \\
\hline T07 & Patos - PB & 23,69 & 49,03 & 3,11 & 4,21 \\
\hline T08 & Patos - PB & 24,27 & 48,88 & 2,83 & 4,97 \\
\hline T09 & Patos - PB & 21,04 & 51,84 & 3,15 & 4,51 \\
\hline T10 & Patos - PB & 24,33 & 47,08 & 4,23 & 5,49 \\
\hline $\mathrm{T} 11$ & Patos - PB & 23,48 & 53,64 & 3,46 & 4,29 \\
\hline T12 & Patos - PB & 23,43 & 49,38 & 3,67 & 4,33 \\
\hline $\mathrm{T} 13$ & Patos - PB & 22,05 & 51,07 & 3,80 & 4,77 \\
\hline $\mathrm{T} 14$ & Patos - PB & 22,84 & 50,37 & 3,49 & 4,47 \\
\hline Média & Patos - PB & 23,16 & 49,64 & 3,30 & 4,53 \\
\hline $\mathrm{P}$ & - & 7,82 E- 10 & $3,13 \mathrm{E}-08$ & $3,23 \mathrm{E}-01$ & $1,04 \mathrm{E}-05$ \\
\hline
\end{tabular}

Rev. Ceres, Viçosa, v. 60, n.3, p. 301-310, mai/jun, 2013 
Tabela 2. Composição em ácidos graxos (\%) do óleo de gergelim de amostras cultivadas em Barbalha - CE

\begin{tabular}{|c|c|c|c|c|c|c|c|c|c|c|c|c|c|c|c|}
\hline \multirow{2}{*}{ ÁCIDO GRAXO } & \multicolumn{15}{|c|}{ Genótipos de Gergelim de Barbalha - CE } \\
\hline & T 01 & T02 & T 03 & T 04 & T 05 & T 06 & T 07 & T 08 & T 09 & T 10 & T 11 & T 12 & T 13 & T 14 & Média \\
\hline $\mathrm{C} 16: 0$ & 9,90 & 10,30 & 10,09 & 9,22 & 10,48 & 10,01 & 10,02 & 9,91 & 10,15 & 9,85 & 9,78 & 9,96 & 10,17 & 10,18 & 10,00 \\
\hline $\mathrm{C} 18: 0$ & 5,00 & 5,36 & 5,52 & 4,90 & 5,42 & 5,47 & 5,67 & 5,35 & 5,16 & 5,44 & 5,47 & 5,58 & 5,32 & 5,35 & 5,36 \\
\hline C18:1 & 37,68 & 37,07 & 35,85 & 40,15 & 37,19 & 37,43 & 37,00 & 38,81 & 36,95 & 36,77 & 38,77 & 36,97 & 36,20 & 37,21 & 37,43 \\
\hline C18:2 & 47,43 & 47,27 & 48,54 & 45,12 & 46,10 & 45,96 & 46,67 & 45,92 & 47,74 & 47,93 & 45,98 & 46,90 & 48,31 & 47,25 & 46,94 \\
\hline C20:0 & traços & traços & traços & 0,61 & traços & 0,60 & 0,64 & traços & traços & traços & traços & 0,58 & traços & traços & - \\
\hline $\mathrm{C} 18: 3$ & traços & traços & traços & traços & traços & traços & traços & traços & traços & traços & traços & traços & traços & traços & - \\
\hline Não identificados & - & - & - & - & 0,82 & 0,53 & - & - & - & - & - & - & - & - & - \\
\hline
\end{tabular}

Tabela 3. Composição em ácidos graxos (\%) do óleo de gergelim de amostras cultivadas em Patos - PB

Genótipos de Gergelim de Patos - PB

\begin{tabular}{|c|c|c|c|c|c|c|c|c|c|c|c|c|c|c|c|}
\hline \multirow{2}{*}{ ÁCIDO GRAXO } & \multicolumn{15}{|c|}{8} \\
\hline & T 01 & T02 & T 03 & T 04 & T 05 & T 06 & T 07 & T 08 & Т 09 & T 10 & T 11 & T 12 & T 13 & T 14 & Média \\
\hline C16:0 & 9,70 & 9,68 & 10,10 & 10,17 & 9,64 & 9,88 & 10,39 & 10,09 & 10,11 & 10,05 & 10,34 & 9,79 & 9,71 & 10,34 & 10,00 \\
\hline C18:0 & 5,72 & 5,61 & 5,75 & 5,99 & 5,74 & 5,83 & 5,89 & 5,58 & 5,38 & 5,74 & 5,77 & 6,13 & 5,57 & 5,61 & 5,74 \\
\hline C18:1 & 39,62 & 40,02 & 39,96 & 40,68 & 39,96 & 39,45 & 39,13 & 41,05 & 37,96 & 39,99 & 39,85 & 41,79 & 38,03 & 39,74 & 39,80 \\
\hline C18:2 & 44,02 & 44,05 & 43,51 & 42,46 & 44,65 & 43,72 & 43,83 & 42,80 & 46,54 & 43,57 & 43,02 & 39,59 & 46,09 & 43,43 & 43,66 \\
\hline $\mathrm{C} 20: 0$ & 0,64 & 0,64 & 0,69 & 0,70 & - & 0,71 & traços & traços & traços & 0,66 & 0,64 & 0,68 & 0,60 & 0,61 & - \\
\hline C18:3 & 0,31 & traços & traços & traços & - & traços & traços & traços & traços & traços & traços & traços & traços & traços & - \\
\hline Não identificados & 0,00 & 0,00 & 0,00 & 0,00 & 0,01 & 0,40 & 0,76 & 0,48 & 0,01 & 0,00 & 0,38 & 2,02 & 0,00 & 0,27 & - \\
\hline
\end{tabular}

(-) não detectado

0,40

(20.78


As diferenças observadas entre os genótipos na mesma localidade são pequenas, mas observou-se diferença entre os locais de cultivo, em virtude de diferenças ambientais, não necessariamente relacionadas com as temperaturas, que foram próximas, mas, possivelmente, relacionadas com a disponibilidade hídrica.

Arslan et al. (2007) reportam que a relação oleico/ linoleico é fortemente influenciada por fatores externos.

A composição em ácidos graxos do óleo é fundamental para os países produtores, pois o padrão de identidade dos óleos baseia-se nos perfis de ácidos graxos e de esteróis. Comparando-se os resultados de ácidos graxos dos genótipos estudados, observou-se que o teor de ácido linoleico das variedades T03 e T13, cultivadas em Barbalha, estão ligeiramente acima da faixa relatada no Codex Alimentarius, de 39,1 a 47,9\%. Assim, resultados de óleos autênticos (obtidos a partir de extração de óleo da semente) podem subsidiar o processo de alteração dessas faixas de composição no
Codex. Ocorrências semelhantes foram encontrados por Antoniassi \& Souza (2001) e por Ross et al. (2007), com resultados ligeiramente fora das faixas relatadas pelo Codex Alimentarius (2001).

Quanto às características do óleo, não houve diferenças entre os resultados de densidade relativa e índice de refração, para as amostras de semente de Patos e de Barbalha ( $\mathrm{p}<0,05)$. Mas algumas diferenças foram observadas em relação ao padrão do Codex Alimentarius (2001), para óleo de gergelim, cuja faixa para densidade relativa a $20^{\circ} \mathrm{C}$ é de 0,915 a 0,924 , enquanto o índice de refração $\left(40^{\circ} \mathrm{C}\right)$ é de 1,465 a 1,469 (Tabela 4$)$.

O resultado médio da acidez do óleo das amostras de Barbalha foi significativamente maior que a média obtida para Patos $(\mathrm{p}<0,05)$, respectivamente de, 2,42 e 1,25\%. A acidez do óleo decorre de hidrólise enzimática, em virtude da umidade da semente e a diferença observada devese, provavelmente, às diferenças de umidade inicial na colheita, da secagem e do armazenamento da semente,

Tabela 4. Características do óleo de semente de genótipos de gergelim

\begin{tabular}{|c|c|c|c|c|c|}
\hline Cultivar & Local de Cultivo & Acidez (\%) & $\begin{array}{c}\text { Teor de matéria } \\
\text { Insaponificável }(\%)\end{array}$ & $\begin{array}{c}\text { Densidade } \\
\text { relativa a } 20^{\circ} \mathrm{C}\end{array}$ & $\begin{array}{c}\text { Índice de } \\
\text { Refração }\left(n_{\mathrm{D}} 40\right)\end{array}$ \\
\hline T01 & Barbalha - CE & 1,67 & 2,17 & 0,916 & 1,4649 \\
\hline T02 & Barbalha - CE & 1,82 & 2,04 & 0,917 & 1,4653 \\
\hline T03 & Barbalha-CE & 2,21 & 1,05 & 0,918 & 1,4655 \\
\hline T04 & Barbalha-CE & 1,79 & 1,94 & 0,921 & 1,4664 \\
\hline T05 & Barbalha-CE & 1,22 & 1,69 & 0,905 & 1,4618 \\
\hline T06 & Barbalha-CE & 0,93 & 1,51 & 0,909 & 1,4631 \\
\hline T07 & Barbalha-CE & 0,73 & 1,94 & 0,900 & 1,4606 \\
\hline T08 & Barbalha - CE & 4,72 & 2,43 & 0,902 & 1,4610 \\
\hline T09 & Barbalha - CE & 4,90 & 1,73 & 0,899 & 1,4594 \\
\hline $\mathrm{T} 10$ & Barbalha-CE & 4,32 & 1,70 & 0,905 & 1,4616 \\
\hline $\mathrm{T} 11$ & Barbalha - CE & 3,07 & 2,24 & 0,919 & 1,4657 \\
\hline $\mathrm{T} 12$ & Barbalha-CE & 2,03 & 1,88 & 0,918 & 1,4657 \\
\hline $\mathrm{T} 13$ & Barbalha - CE & 2,14 & 1,89 & 0,921 & 1,4669 \\
\hline $\mathrm{T} 14$ & Barbalha-CE & 2,37 & 1,46 & 0,921 & 1,4665 \\
\hline Média & Barbalha - CE & 2,42 & 1,83 & 0,912 & 1,4639 \\
\hline T01 & Patos - PB & 1,37 & 1,27 & 0,913 & 1,4639 \\
\hline T02 & Patos - PB & 1,28 & 1,23 & 0,917 & 1,4649 \\
\hline T03 & Patos - PB & 1,13 & 1,41 & 0,919 & 1,4651 \\
\hline T04 & Patos - PB & 1,36 & 1,18 & 0,912 & 1,4633 \\
\hline T05 & Patos - PB & 1,45 & 2,67 & 0,918 & 1,4652 \\
\hline T06 & Patos - PB & 1,24 & 1,33 & 0,912 & 1,4633 \\
\hline T07 & Patos - PB & 0,90 & 0,86 & 0,918 & 1,4650 \\
\hline T08 & Patos - PB & 1,44 & 1,67 & 0,915 & 1,4642 \\
\hline T09 & Patos - PB & 1,29 & 1,37 & 0,916 & 1,4646 \\
\hline $\mathrm{T} 10$ & Patos - PB & 1,58 & 1,22 & 0,916 & 1,4639 \\
\hline $\mathrm{T} 11$ & Patos - PB & 0,80 & 1,33 & 0,903 & 1,4606 \\
\hline $\mathrm{T} 12$ & Patos - PB & 1,28 & 0,8 & 0,910 & 1,4625 \\
\hline T13 & Patos - PB & 1,23 & 1,24 & 0,917 & 1,4650 \\
\hline $\mathrm{T} 14$ & Patos - PB & 1,21 & 1,84 & 0,913 & 1,4631 \\
\hline Média & Patos - PB & 1,25 & 1,39 & 0,914 & 1,4639 \\
\hline $\mathrm{p}$ & & 1,39 E-05 & 3,95 E-05 & $4,25 \mathrm{E}-05$ & 3,91 E-06 \\
\hline
\end{tabular}

Rev. Ceres, Viçosa, v. 60, n.3, p. 301-310, mai/jun, 2013 
Tabela 5. Composição em esteróis (\%)* do óleo de gergelim de amostras cultivadas em Barbalha - CE

\begin{tabular}{|c|c|c|c|c|c|c|c|c|c|c|c|c|c|c|c|}
\hline \multirow{2}{*}{ ESTEROL } & \multicolumn{15}{|c|}{ Genótipos de Gergelim de Barbalha - CE } \\
\hline & T01 & T02 & T03 & T04 & T05 & T06 & T07 & T08 & T09 & T10 & T11 & T12 & T13 & T14 & Média \\
\hline Campesterol & 15,86 & 17,18 & 16,64 & 14,93 & 15,74 & 16,63 & 15,85 & 15,55 & 16,6 & 15,91 & 15,1 & 15,51 & 15,96 & 16,27 & 16,00 \\
\hline Estigmasterol & 6,50 & 7,00 & 7,12 & 7,71 & 7,38 & 7,74 & 7,17 & 7,83 & 7,48 & 6,77 & 6,71 & 7,47 & 6,73 & 7,68 & 7,22 \\
\hline Beta-sitosterol & 59,82 & 60,26 & 58,31 & 59,81 & 61,64 & 60,53 & 60,61 & 58,81 & 60,15 & 60,42 & 59,26 & 58,99 & 59,44 & 58,85 & 59,64 \\
\hline Delta 5 avenasterol & 12,94 & 11,72 & 12,1 & 13,22 & 11,31 & 10,35 & 11,07 & 12,87 & 11,3 & 11,3 & 12,95 & 12,76 & 12,72 & 11,91 & 12,09 \\
\hline Delta 7 estigmastenol & $\operatorname{Tr}$ & $\operatorname{Tr}$ & 0,44 & $\operatorname{Tr}$ & $\operatorname{Tr}$ & $\operatorname{Tr}$ & 0,33 & $\operatorname{Tr}$ & 0,26 & 0,44 & 0,38 & 0,30 & 0,28 & 0,35 & 0,35 \\
\hline Delta 7 avenasterol & 0,86 & 0,51 & 0,85 & 0,49 & 0,72 & 0,62 & 0,61 & 0,75 & 0,71 & 0,82 & 0,74 & 0,80 & 0,64 & 0,70 & 0,7 \\
\hline Não identificados & 4,02 & 3,33 & 4,54 & 3,84 & 3,21 & 4,13 & 4,36 & 4,19 & 3,5 & 4,34 & 4,86 & 4,17 & 4,23 & 4,24 & - \\
\hline
\end{tabular}

* valores expressos do esterol no total de esteróis

$\operatorname{Tr}-\operatorname{traços}$

- não realizado

Tabela 6. Composição em esteróis (\%)* do óleo de gergelim de amostras cultivadas em Patos - PB

ESTEROL Genótipos de Gergelim de Patos - PB

Campester

Campesterol

$\begin{array}{llll}\text { T01 } & \text { T02 } & \text { T03 } & \text { T04 }\end{array}$

$\begin{array}{lll}\text { T06 } & \text { T07 } & \text { T08 }\end{array}$

T09

T10

T11

T12

T13

T14 Média

Estigmastero

$\begin{array}{rrrr}15,26 & 15,78 & 16,48 & 15,32\end{array}$

$16,19 \quad 15,59$

$16,31 \quad 16,18$

$\begin{array}{rr}15,3 & 15,45 \\ 6,63 & 6,3\end{array}$

$\begin{array}{lrrrr}\text { Beta-sitosterol } \quad 65,48 & 64,29 & 65,66 & 65,52\end{array}$

$\begin{array}{lllll}\text { Delta } 5 \text { avenasterol } \quad 7,97 & 8,64 & 7,45 & 7,92\end{array}$

$\begin{array}{lllllll}\text { Delta } 5 \text { avenasterol } & 7,97 & 8,64 & 7,45 & 7,92 & - \\ \text { Delta } 7 \text { estigmastenol } & 0,57 & 0,33 & 0,35 & 0,43 & - & \text { Tr }\end{array}$

Delta 7 avenasterol

Não identificados

$\begin{array}{llll}0,86 & 0,85 & 0,73 & 0,75 \\ 3,93 & 3,44 & 2,67 & 3,23\end{array}$

* valores expressos do esterol no total de esteróis

$\operatorname{Tr}$ - traços 
entre as duas localidades. A acidez do óleo deve ser mantida o mais baixa possível já que valores elevados influenciam na sua aceitabilidade; além disso, na legislação brasileira, o limite de acidez para óleos prensados a frio e não refinados é de $4 \mathrm{mg} \mathrm{KOH} / \mathrm{g}$ ou $2 \%$ de ácidos graxos livres (Brasil, 2005).

Houve diferença significativa no teor de material insaponificável entre os óleos obtidos de sementes de Patos e de Barbalha, com médias de 1,39 e 1,83\%, respectivamente (Tabela 4). A matéria insaponificável inclui esteróis, tocoferóis e substâncias com atividade antioxidante.

Quanto aos esteróis, houve diferença significativa entre as amostras analisadas $(\mathrm{p}<0,05)$. Os teores de campesterol, estigmasterol e delta 5 avenasterol foram maiores para amostras de Barbalha, enquanto o de sitosterol foi maior para amostras de Patos. As diferenças observadas entre as variedades num mesmo local foram pequenas, mas observou-se diferença entre os locais de cultivo (Tabelas 5 e 6 ).

No perfil de esteróis de óleo de gergelim (Figura 2), observa-se a presença de sesamina e sesamolina, que são antioxidantes naturais presentes na semente de gergelim. Para obtenção da fração de esteróis, realizou-se um fracionamento do material insaponificável por cromatografia de camada delgada, recuperando-se além dos esteróis, a sesamina e sesamolina, características dessa oleaginosa. A quantificação desses antioxidantes naturais em diferentes condições de cultivo de gergelim é de interesse numa avaliação futura.

Os resultados obtidos para campesterol e estigmasterol são compatíveis com as faixas reportadas pelo Codex Alimentarius (2001), enquanto os resultados obtidos para sitosterol e delta 5 avenasterol estão acima das faixas relatadas, de 57,7 a $61,9 \%$ e de 6,2 a 7,8\%, respectivamente. Da mesma maneira como ocorrido para composição em ácidos graxos, o perfil de esteróis é utilizado para definir o padrão de identidade e os paí-

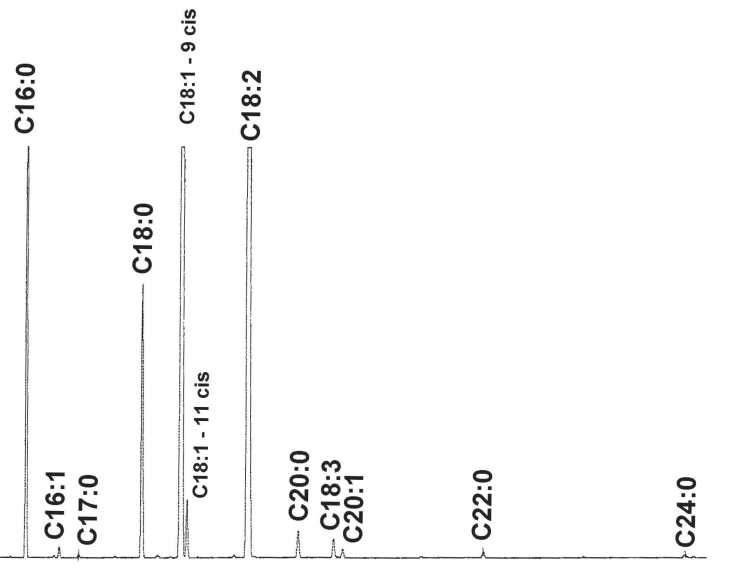

Figura 1. Cromatograma de ácidos graxos de óleo de gergelim por CGAR.

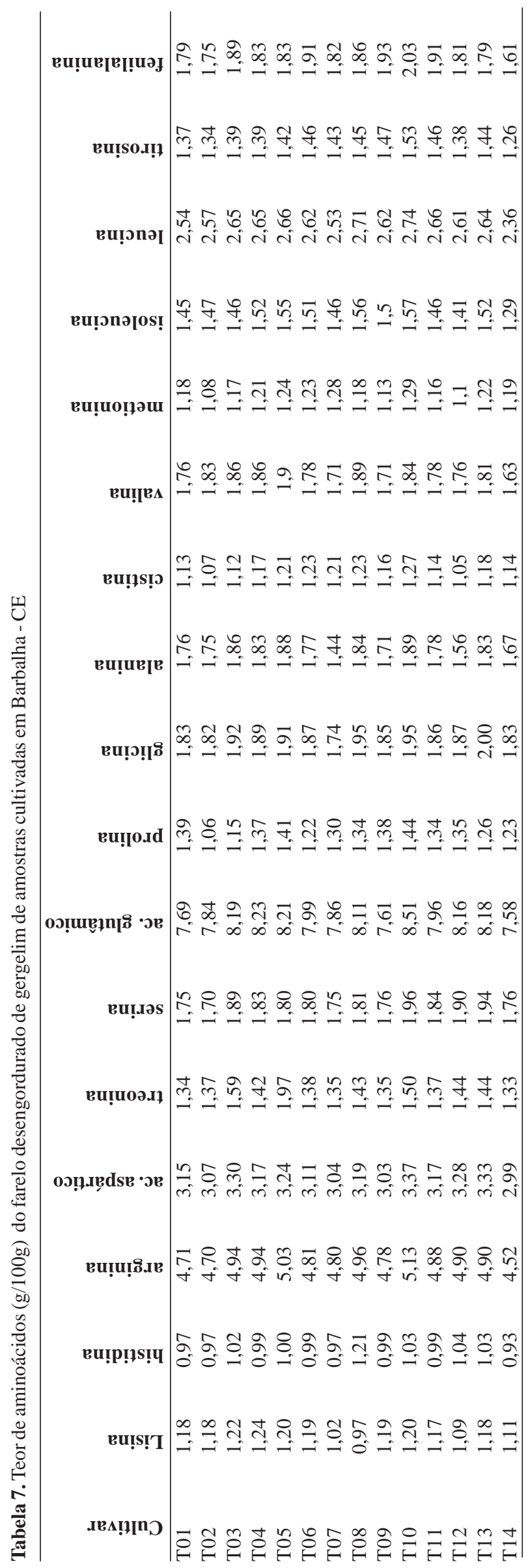

Rev. Ceres, Viçosa, v. 60, n.3, p. 301-310, mai/jun, 2013 


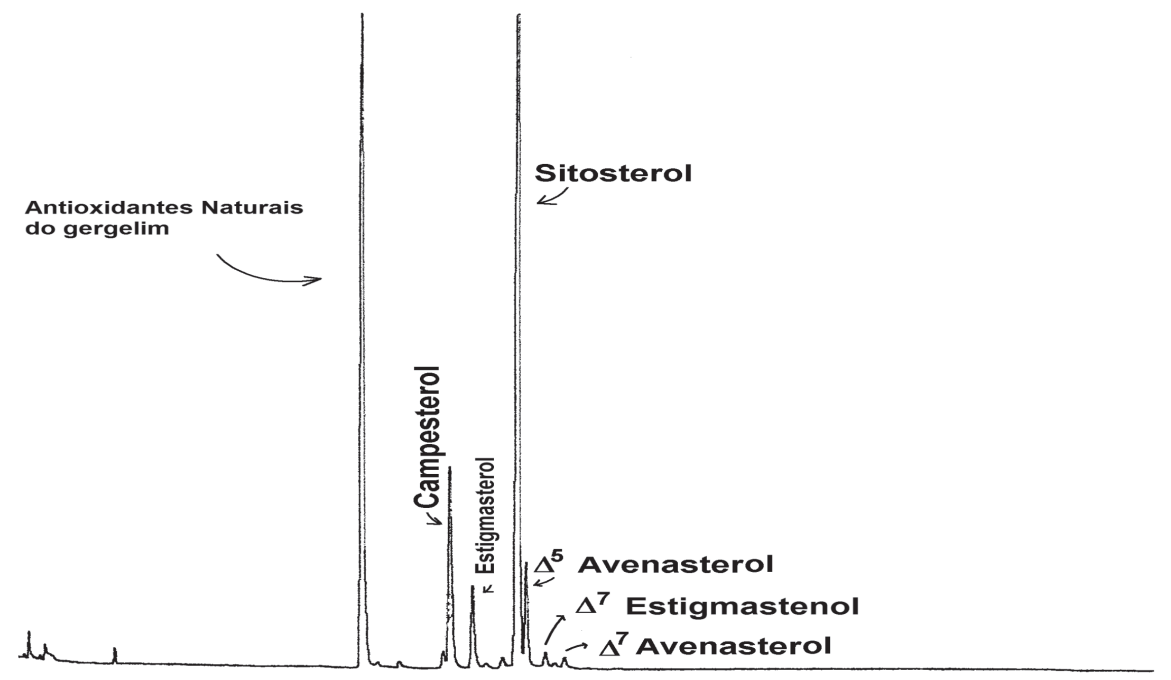

Figura 2. Cromatograma de íons totais da fração de esteróis de óleo de gergelim por CGAR/EM.

ses podem pleitear ao Codex Alimentarius a alteração do padrão, baseando-se em resultados de variedades locais.

A avaliação de composição de genótipos e de variedades cultivadas no Brasil pode subsidiar a alteração do padrão de identidade de óleos do Codex Alimentarius, utilizado no mercado internacional e adotado por vários países, inclusive o Brasil, na RDC 270 (Brasil, 2005). Os óleos de gergelim obtidos a partir destes genótipos não atenderiam ao padrão de identidade exigido na referida legislação e no Codex Alimentarius, o que representa entraves para sua comercialização.

Quanto aos aminoácidos do farelo desengordurado de gergelim, não houve diferença entre as variedades e optou-se por realizar a análise apenas nas amostras de Barbalha (Tabela 7). Os resultados obtidos são semelhantes a outros, relatados na literatura, mas ligeiramente inferiores àqueles da tabela de composição de alimentos norte-americana (USDA, 2013). Diferenças entre resultados devem-se à base de cálculo, pois, em geral, os resultados de aminoácidos estão expressos em g/100 gramas de amostra, em virtude da rotulagem nutricional, mas outros são relatados em mg/grama de proteína. Entre as proteínas vegetais, o gergelim apresenta, como particularidade, teores elevados de metionina, cisteína, arginina e leucina, mas é deficiente em lisina (Namiki, 2007; Maia et al., 1999).

\section{CONCLUSÕES}

O conteúdo de óleo das sementes de gergelim foi influenciado pela disponibilidade hídrica, durante o estádio de desenvolvimento das plantas. Houve alteração da composição do óleo entre os locais estudados quanto aos ácidos graxos e esteróis, mas não houve diferenças entre os genótipos.

\section{REFERÊNCIAS}

Antoniassi R \& Souza DFS (2001) Composição, processamento e atividade antioxidante. In: Beltrão NEM \& Vieira DJ (Eds.) O agronegócio do gergelim no Brasil. Brasília, Embrapa Informação Tecnológica. 348p.

AOAC - Official methods of analysis of AOAC International (2010a) $18^{\text {th }}$ ed. Gaithersburg, AOAC, Chapter 33, Official Method 33.2.11. p.10-12.

AOAC - Official methods of analysis of AOAC International (2010b) $18^{\text {th }}$ ed. Gaithersburg, AOAC, Chapter 4, Official Method 4.6.02. p.47-48.

AOAC - Official methods of analysis of AOAC International (2010c) $18^{\text {th }}$ ed. Gaithersburg, AOAC, Chapter 4, Official Method 4.1.11. p.9-19.

AOCS - American Oil Chemists' Society (2009) Official methods and recommended practices of the American Oil Chemists' Society. Champaign, AOCS.

Arriel NHC (2006) Cultivo do gergelim. Disponível em: <http:// sistemasdeproducao.cnptia.embrapa.br/FontesHTML/Gergelim/ CultivodoGergelim/autores.html>. Acessado em: 30 de maio de 2010.

Arslan C, Uzun B, Ulger S \& Cagirgan MI (2007) Determination of oil content and fatty acid composition of sesame mutants suited for intensive management conditions. Journal of the American Oil Chemists Society, 84:917-920.

Brasil (1972) Ministério da Agricultura. Equipe de Pedologia e Fertilidade do Solo. Levantamento exploratório: levantamento dos solos do Estado da Paraíba. Rio de Janeiro, Sudene. 683p. (Boletim Técnico, 15).

Brasil (2005) Resolução RDC ANVISA/MS n 270, de 22 de setembro de 2005. Regulamento técnico para óleos vegetais, gorduras vegetais e creme vegetal. Diário Oficial da União, Brasília, DF, 23 de setembro de 2005. Seção 1.

Codex Alimentarius (2001) Fats, Oils and related products. $2^{\text {nd }}$ ed. Roma, FAO/WHO. 80p.

Departamento Nacional De Meteorologia (1992) Normais climatológicas. Brasília, Dnmet. 495p.

El Khier MKS, Ishag KEA \& Yagoub AEA (2008) Chemical composition and oil characteristics of sesame seed cultivars grown in Sudan. Research Journal of Agriculture and Biological Sciences, 4:761-766.

Rev. Ceres, Viçosa, v. 60, n.3, p. 301-310, mai/jun, 2013 
Egbekun MK \& Ehieze MU (1997) Proximate composition and functional properties of fullfat and defatted beniseed (Sesamum indicum L.) flour. Plant Foods Human Nutrition, 51:35-41.

Elleuch M, Besbes S, Roiseux O, Blecker C \& Attia H (2007) Quality characteristics of sesame seeds and by-products. Food Chemistry, 103:641-650.

Embrapa - Empresa Brasileira De Pesquisa Agropecuária (1999) Sistema Brasileiro de Classificação de Solos. Rio de Janeiro, Embrapa - Solos. 412p. (Documento, 15)

Embrapa Algodão (1991) Relatório técnico anual 1987-1989. Campina Grande, Embrapa Algodão. 629p.

FAO - Food and Agriculture Organization of the United Nations (2012) FAOSTAT Production Crops. [on-line]. Disponível em < http://faostat3.fao.org/home/\#DOWNLOAD> Acessado em: 11 de março de 2013.

Hartman L \& Lago RC (1973) Rapid determination of fatty acid methyl esthers from lipids. Laboratory Practice, 2:475-494.

Hwang LS (2005) Sesame oil. In: Shahidi F (Ed.) Bailey's Industrial Oil \& Fat Products. $6^{\text {th }}$ ed. New York, Wiley-Interscience. p. $537-75$

IAC - Instituto Agronômico de Campinas (2010) Cultivares. Cultura de gergelim. Disponível em: <http://www.iac.br/cultivares/ inicio/Folders/Gergelim/IACOuro.htm>. Acessado em: 13 de Março de 2013.

Jones DB (1931) Factors for converting percentages of nitrogen in foods and feeds into percentagens of protein. Washington DC, US Department of Agriculture. (Circular, $\mathrm{n}^{\circ}$ 183)
Kemal Ünal M \& Yalçin H (2008) Composición de semillas de sésamo de Turquía y caracterización de sus aceites. Grasas y Aceites, 59:23-26.

Maia GA, Calvete YMA, Telles FJS, Monteiro JCS \& Sales GM (1999) Eficiência da farinha desengordurada de gergelim como complemento protéico da farinha extrudada de caupi. Pesquisa Agropecuária Brasileira, 34:1295- 1303.

Namiki M (2007) Nutraceutical Functions of Sesame: A Review. Critical Reviews in Food Science and Nutrition, 47:651-673.

Ross Junior IG, Basso EA, Bezerra AR \& Antoniassi R (2007) Rendimento em óleo das variedades de gergelim cultivadas no Estado do Rio de Janeiro para o projeto Riobiodiesel. In: VII Congresso Brasileiro de Engenharia Química em Iniciação Cientifica, São Carlos. Anais, DEQ/Universidade Federal de São Carlos. CD-ROM

USDA (2013) - United States Department of Agriculture. Agricultural Research Service. Nutrient Data Laboratory. Disponível em: <http://ndb.nal.usda.gov/ndb/search/list >. Acessado em: 13 de Março de 2013.

Were BA, Onkware AO, Gudu S, Welander M \& Carlsson AS (2006) Seed oil content and fatty acid composition in east African sesame (Sesamum indicum L.) accessions evaluated over 3 years. Field Crops Research, 97:254-260. 